\title{
Facetas cerâmicas: uma análise minimamente invasiva na odontologia
}

Ceramic facets: minimally invasive analysis in dentistry

Facetas cerámicas: un análisis mínimamente invasivo en odontología

José Milton de Aquino e Silva Neto ${ }^{1 *}$, Sysllânia Vitória Pôrto Souza ${ }^{1}$, Moisés Pereira Casado de Farias ${ }^{1}$, João Vitor Brasil Alves Rodrigues Almeida Barros ${ }^{1}$, Júllian Karen Bezerra dos Santos ${ }^{1}$, Michelle Leão Bittencourt Brandão Medeiros ${ }^{1}$, Tayguara Cerqueira Cavalcanti' .

\section{RESUMO}

Objetivo: Realizar uma revisão de literatura para analisar as indicações das facetas em cerâmicas de forma minimamente invasiva pelos Cirurgiões Dentistas (CD). Métodos: Como estratégia de busca foi estabelecido pesquisas nas bases de dados PubMed/MedLine, LiLacs e SciELo, no período de 2015-2020, combinando os descritores "facetas", "facetas em cerâmicas" e "odontologia estética" aos descritores booleanos nas respectivas fontes de pesquisa. Resultados: Nas últimas décadas a utilização da cerâmica pelo CD vem sendo cada vez mais utilizada, quando se compara os preparos feitos em facetas laminadas e a utilização das coroas totais observa-se que a utilização de facetas torna-se o desgaste dental menos invasivo, um dos motivos desse fato deve-se ao nível de escurecimento do dente, desta forma a designação do clareamento dos elementos dentais prévio se faz necessário para um resultado final do tratamento mais positivo e minimamente invasivo. Considerações Finais: A utilização das facetas indiretas tem se apresentado bastante eficiente e é na atualidade apontado como sendo o procedimento de eleição em casos de elementos dentais bastante escurecidos e extensamente restaurados, porém, os profissionais devem classificar e qualificar, de maneiras distintas, as particularidades de cada caso para só assim poder garantir um melhor resultado final do tratamento.

Palavras-chave: Cerâmica, Facetas dentárias, Estética dentária.

\begin{abstract}
Objective: Conduct a literature review to analyze the indications of facets in ceramics in a minimally invasive manner by dental surgeons (CD). Methods: As a search strategy, research was established in the databases PubMed/MedLine, LiLacs and SciELo, in the period 2015-2020, combining the descriptors "facets", "ceramic facets" and "cosmetic dentistry" to the Boolean descriptors in the respective sources, search. Results: In the last decades, the use of ceramic by the $C D$ has been increasingly used, when comparing the preparations made in laminated veneers and the use of full crowns it is observed that the use of veneers becomes less invasive dental wear, one of the reasons for this fact are due to the level of darkening of the tooth, so the designation of the whitening of the previous dental elements is necessary for a final result of the most positive and minimally invasive treatment. Final Considerations: The use of indirect facets has been shown to be quite efficient and is currently considered to be the procedure of choice in cases of very darkened and extensively restored dental elements, however, professionals must classify and qualify, in different ways, the particularities of each case, in order to guarantee a better final result of the treatment.
\end{abstract}

Keywords: Ceramics, Dental veneers, Dental esthetic.

${ }^{1}$ Centro Universitário CESMAC (CESMAC), Maceió - AL.

*E-mail: Milton_neto_166@hotmail.com 


\section{RESUMEN}

Objetivo: Realice una revisión de la literatura para analizar las indicaciones de facetas en cerámica de una manera mínimamente invasiva por parte de los cirujanos dentales (CD). Métodos: Como estrategia de búsqueda, la investigación se estableció en las bases de datos PubMed/MedLine LiLacs y SciELo, en el período 2015-2020, combinando los descriptores "facetas", "facetas cerámicas" y "odontología cosmética" con los descriptores booleanos em las fuentes respectivas, investigación. Resultados: En las últimas décadas, el uso de cerámica por parte del CD se há utilizado cada vez más, al comparar las preparaciones hechas en carillas laminadas y el uso de coronas completas, se observa que el uso de carillas se convierte en un desgaste dental menos invasivo, uno de los las razones de este hecho se deben al nivel de oscurecimiento del diente, por lo que la designación del blanqueamiento de los elementos dentales anteriores es necesaria para un resultado final del tratamiento más positivo y mínimamente invasivo. Consideraciones finales: Se ha demostrado que el uso de facetas indirectas es bastante eficiente y actualmente se considera el procedimiento de elección en casos de elementos dentales muy oscurecidos y muy oscurecidos y ampliamente restaurados, sin embargo, los profesionales deben clasificar y calificar, de diferentes maneras, las particularidades de cada caso, para garantizar un mejor resultado final del tratamiento.

Palabras clave: Cerámica, Coronas con frente estético, Estética dental.

\section{INTRODUÇÃO}

O grande avanço dos procedimentos estéticos vem fazendo com quer a busca cada vez mais constante dos pacientes cresçam, devido esses fatores os profissionais buscam cada vez mais se qualificar para atender as expectativas esperadas do público alvo, priorizando por sua vez os alinhamentos, o visagismo facial e o restabelecimento não só estético como funcional dos elementos dentais (CALIXTO R e MASSING N, 2015).

Os materiais resinosos de uso direto utilizados no consultório odontológico, buscam restabelecer a anatomia do elemento dental que encontra-se com algum tipo de desgaste, provocado por inúmeros fatores, fazendo por sua vez a correção de ângulos incisais, saliências de esmalte em locais específicos e eventuais sulcos de desenvolvimento que não estejam padronizados (GREGORINI CM, 2018).

Nos consultórios odontológicos, uma das principais lamentações mais existente entre os pacientes é o desagrado com a estética dos dentes, encontrando-se as possíveis causas decorrentes da combinação de inúmeros fatores. O progresso da área Odontológica relacionada aos sistemas adesivos possibilitou a melhoria da união anatômica, fisiológica e mecânica entre os elementos dentais e as restaurações, aprimorando e aperfeiçoando as metodologias que se refere aos agentes restauradores e consentindo uma interpelação mais conservadora e minimamente invasiva (ACT A, 2018).

Na busca por sorrisos mais harmônicos e padronizados esteticamente inúmeras opções restauradoras de forma direta e indireta existem no mercado, levando em consideração as diversas imposições e perspectivas dos indivíduos, afligimento no que se refere à resistência e duração da restauração, remoção da configuração estrutural dentária integra, quantidade de sessões necessárias para o fim do tratamento e por fim porém não menos importante o valor do tratamento que devem ser conhecida no decorrer da elaboração do plano de tratamento (CALIXTO R e MASSING N, 2015).

A aplicação das facetas pode ser feita de duas formas: tanto direta, quanto indireta. As que são realizadas e aplicadas pelo Cirurgião Dentista é a técnica direta, visto que podem ser desenvolvidas com as resinas compostas, já as facetas indiretas abrangem além do serviço do $C D$ a parte laboratorial do técnico em prótese dentária e dos quais podem serem constituídas tanto de resinas compostas de forma indireta (cerômeros) quanto de porcelana (GREGORINI CM, 2018).

Os processos restauradores diretos executados com resinas compostas possibilitam uma forma de técnica minimamente invasiva, tendo como principal objetivo os cuidados com as estruturas dentais, preservando o máximo possível, sendo comparado com os procedimentos realizados nas restaurações indiretas (PERSCH 
$\mathrm{DL}$, et al., 2017). As facetas indiretas possuem uma forma menos conservadora dos elementos dentais íntegros, implicando desta forma em uma maior quantidade de perda das estruturas do tecido dental, especialmente no que se refere aos casos de escurecimento da coroa. Levando-se em comparação com coroas que são totalmente fabricadas, as facetas estéticas, tanto as que se referem a técnica direta ou indireta, demonstram algumas vantagens bastante representativas (OLIVEIRA CHO, 2018).

Com o melhoramento dessas técnicas no que se refere as suas aplicações e o aperfeiçoamento dos materiais utilizados, as facetas de cerâmica vêm se tornando cada vez mais utilizadas como sendo uma alternativa ao que se refere a reabilitação oral de forma minimamente invasiva, nos dias de hoje, o comprometimento de forma mínima ao que se refere ao desgaste dental é uma das etapas que devem serem levadas como critério fundamental para o planejamento da harmonização dental (OLIVEIRA CHO, 2018).

Assim sendo, este trabalho tem como principal fundamento, através de uma revisão de literatura, realizar uma revisão integrativa sobre os procedimentos minimamente invasivos utilizados na odontologia, desenvolvendo um estudo sobre facetas cerâmicas observando suas indicações e contraindicações, vantagens e desvantagens.

\section{MÉTODOS}

Esta pesquisa atribui-se por meio de uma revisão de literatura estabelecida entre os períodos de junho de 2019 a março de 2020, onde foram avaliados artigos publicados em bases de dados eletrônicos Literatura Latino Americana e do Caribe em Ciências da Saúde (LILACS), Literatura Internacional em Ciência da Saúde (MEDLINE) e Scientific Electronic Library Online(SCIELO) e livros que estavam disponíveis nos acervos bibliográficos presentes na biblioteca central do Centro de Ensino Superior de Maceió (CESMAC).

Para tal o estudo foi determinado através das seguintes normas: os desenhos dos estudos deveriam ser ensaios clínicos controlados randomizados em humanos, os artigos incluídos estavam no idioma, português, inglês e espanhol, sendo determinado os trabalhos publicados nos últimos 5 anos (2015 a 2020) que se mencionaram aos procedimentos minimamente invasivos utilizando as facetas cerâmicas, possuindo como processo de exclusão os períodos de publicações, relatos de casos, estudos em animais, ensaios não controlados, monografias e os artigos que não possuíam relevância com a temática, sendo eleitos os textos científicos que apresentavam na íntegra o real objetivo do trabalho, observando a importância da diferenciação das técnicas diretas e indiretas das facetas cerâmicas utilizadas na odontológica, buscando dessa forma a melhor técnica para a obtenção de resultados satisfatórios e benéficos para o paciente.

Os descritores utilizados foram: Facetas, facetas em cerâmicas e odontologia estética. Os artigos foram estabelecidos por 7 pesquisadores: inicialmente foram feitas as considerações da temática e em seguida, foi estabelecida a leitura crítica do resumo para a investigação dos discernimentos de exclusão.

Logo em seguida foram firmadas a leitura de todos eles, as quais se extraíram os subsídios de importância, como também foram verificadas suas listas de referências, buscando encontrar artigos complementares para o enriquecimento científico da revisão. Com os artigos estabelecidos, foram tabuladas as centrais variáveis de instância, como a grandeza da amostra, o objetivo, a metodologia, os parâmetros analisados e os fundamentais resultados.

A princípio, foram estabelecidos 22 artigos referentes a utilização das facetas de cerâmicas na odontologia. Dos quais, 10 estavam repetidos nas respectivas bases de dados, estabelecendo-se dessa forma 12 artigos para o processo de leitura dos títulos, dos quais 3 foram excluídos por não corresponder as principais adaptações dos critérios que estavam sendo focados.

9 artigos designados para observação dos resumos, dos quais três foram excluídos, ficando apenas 6 para assegurar esse estudo. Ao fim das investigações dos dados, a revisão foi mesclada ocorrendo o processo de miscigenação dos seis artigos, e o fluxograma da Figura 1 demonstra com clareza os artifícios de pesquisas elegidas para a confecção desta revisão. 
Figura 1 - Fluxograma dos estudos identificados.

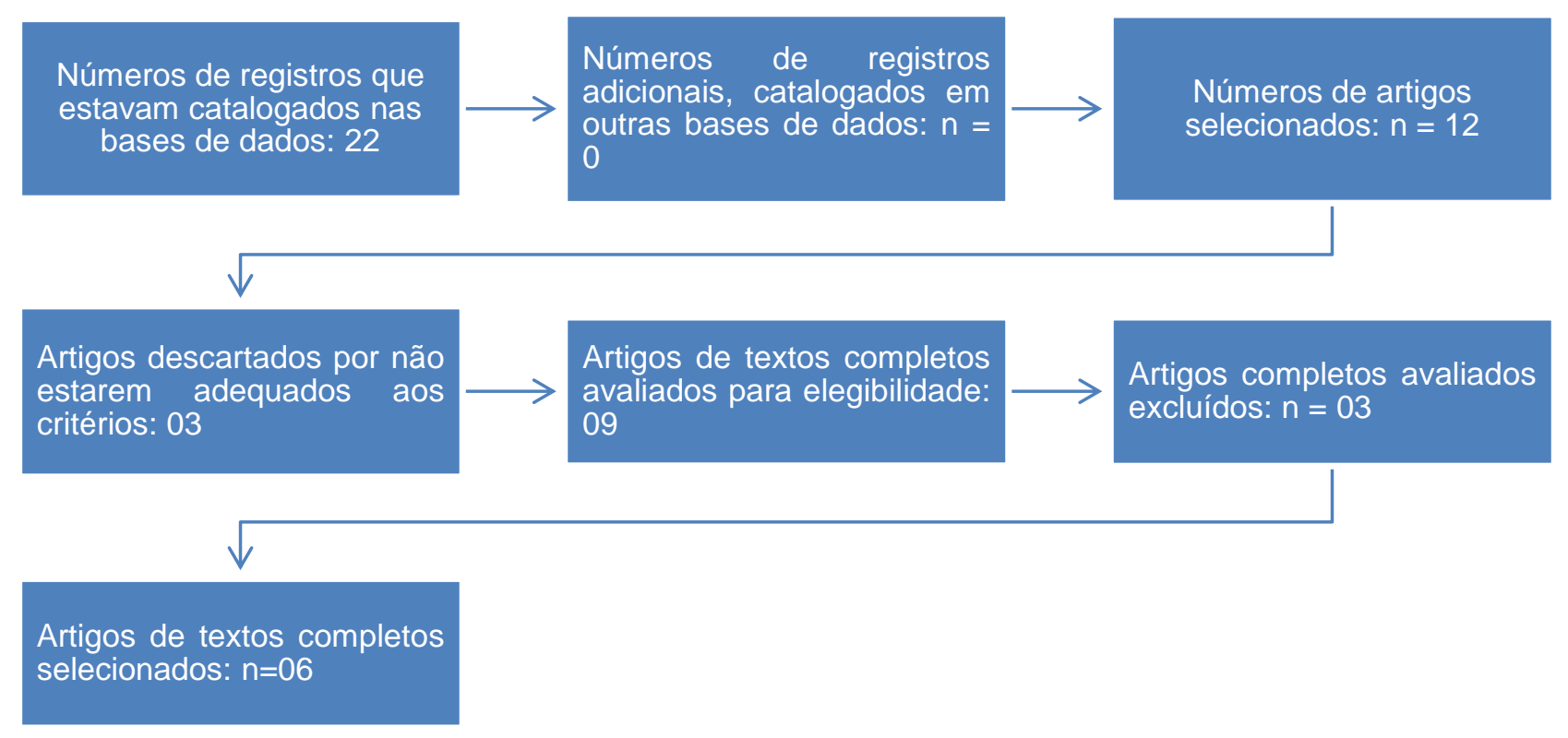

Fonte: Neto JMAS, et al., 2019.

\section{RESULTADOS E DISCUSSÃO}

De acordo com as análises e resultados da pesquisa do presente trabalho, foram selecionados 06 artigos mais recentes e mais utilizados na área odontológica onde foram debatidos e analisados na luz do entendimento da importância do respectivo tema (Quadro 1). 


\section{Revista Eletrônica Acervo Saúde / Electronic Journal Collection Health ｜ ISSN 2178-2091}

Quadro 1 - Distribuição das referências dos artigos selecionados por autor, ano de publicação, país, objetivo, resultados e conclusão, n=06. Maceió - AL, 2020.

\begin{tabular}{|c|c|c|c|c|c|}
\hline Autor & Ano & País & Objetivo & Resultados & Conclusão \\
\hline Moura AB. & 2017 & Brasil & $\begin{array}{c}\text { Realizar uma revisão de literatura, } \\
\text { comparando diferentes abordagens } \\
\text { quanto ao uso de facetas } \\
\text { cerâmicas e de resina composta, } \\
\text { detalhando suas características } \\
\text { físio-químico-mecânicas, } \\
\text { comparando suas vantagens e } \\
\text { indicações e contraindicações. }\end{array}$ & $\begin{array}{c}\text { A odontologia restauradora } \\
\text { avança a passos largos no } \\
\text { campo cientifico, desenvolvendo } \\
\text { materiais com propriedades } \\
\text { mecânicas e estéticas cada vez } \\
\text { mais eficazes. }\end{array}$ & $\begin{array}{c}\text { A realização de uma odontologia de alto } \\
\text { nível e com resultados previsíveis, faz- } \\
\text { se necessário conhecer detalhadamente } \\
\text { cada material restaurador a ser utilizado } \\
\text { desde que seja executada sob a ótica } \\
\text { de protocolos consagrados na } \\
\text { odontologia científica. }\end{array}$ \\
\hline $\begin{array}{l}\text { Persch DL e } \\
\text { sousa NDP. }\end{array}$ & 2017 & Brasil & $\begin{array}{c}\text { Apresentar achados na literatura } \\
\text { sobre as vantagens e } \\
\text { desvantagens de faceta indireta em } \\
\text { porcelana. }\end{array}$ & $\begin{array}{l}\text { As facetas de porcelana tem } \\
\text { demonstrado ótimo resultado } \\
\text { estético e tratamento } \\
\text { conservador devido à } \\
\text { diminuição da espessura da } \\
\text { peça protética, preservando } \\
\text { estrutura dental. }\end{array}$ & $\begin{array}{l}\text { A porcelana no uso de confecção de } \\
\text { facetas se destaca por suas vantagens } \\
\text { onde encontra-se o fato desta ser } \\
\text { confeccionada fora do meio bucal, } \\
\text { através de laboratório, proporcionando } \\
\text { assim conforto ao paciente. }\end{array}$ \\
\hline Gregorini CM. & 2018 & Brasil & $\begin{array}{l}\text { O objetivo deste trabalho foi } \\
\text { realizar uma revisão de literatura } \\
\text { sobre as facetas dentárias, } \\
\text { determinar as indicações e as } \\
\text { contraindicações e comparar as } \\
\text { vantagens e desvantagens das } \\
\text { facetas de resina composta e das } \\
\text { facetas de cerâmicas. }\end{array}$ & $\begin{array}{c}\text { Para tal podem ser } \\
\text { confeccionadas pela técnica } \\
\text { direta utilizando a resina } \\
\text { composta ou indireta, pelo uso } \\
\text { de cerâmica. E é o papel do } \\
\text { Cirurgião Dentista ter o } \\
\text { conhecimento sobre as } \\
\text { propriedades dos materiais e a } \\
\text { técnica. }\end{array}$ & $\begin{array}{l}\text { Conclui-se que diante de vários estudos } \\
\text { realizados, para cada uma das técnicas, } \\
\text { cabe ao Cirurgião Dentista juntamente } \\
\text { com o paciente escolher a melhor } \\
\text { técnica para o caso em específico. }\end{array}$ \\
\hline
\end{tabular}

REAS/EJCH | Vol.Sup.n.48 | e3374 | DOI: https://doi.org/10.25248/reas.e3374.2020 Página 5 de 10 


\section{Revista Eletrônica Acervo Saúde / Electronic Journal Collection Health ～ISSN 2178-2091}

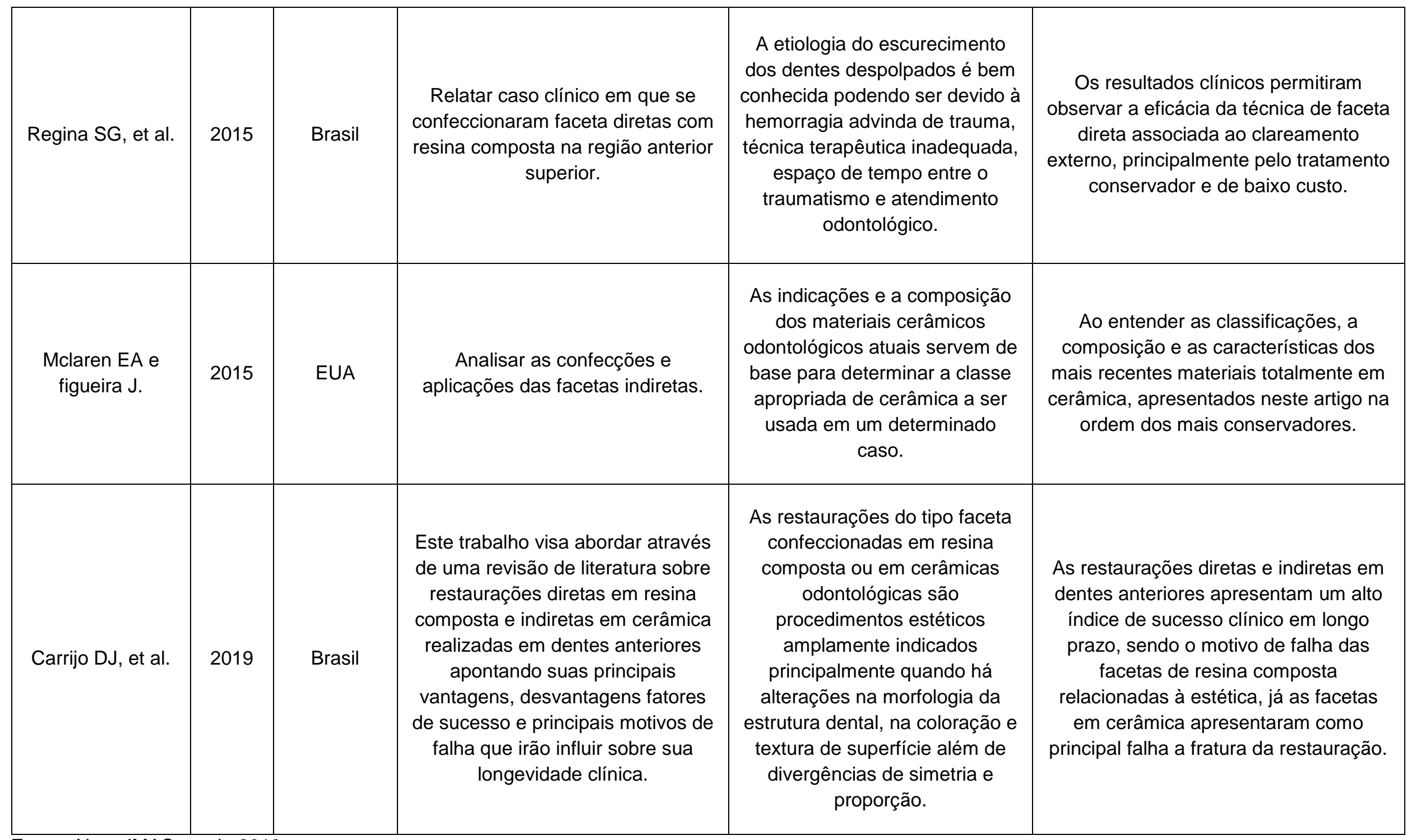

Fonte: Neto JMAS, et al., 2019.

REAS/EJCH | Vol.Sup.n.48 | e3374 | DOI: https://doi.org/10.25248/reas.e3374.2020 Página 6 de 10 
Atualmente, os padrões de estética contribuem de forma direta na sociedade, fazendo com quer as pessoas busquem melhorar sua aparência não só física como também facial. Desse modo, é normal observar que cada vez mais as pessoas buscam modificar seu sorriso, pelo meio da odontologia estética. A estética dental vem se tornando um fator relevante na aparência pessoal, visto que possuir um belo sorriso com elementos dentais impecáveis passou a ser julgado como critério indispensável para a evolução do crescimento não só pessoal, como também profissional. Essas novas concepções sobre o que é belo vem propagando-se principalmente nas última décadas, fazendo com quer os Cirurgiões Dentistas busquem melhoramento através de novas técnicas e materiais de aplicação, como é o caso das cerâmicas odontológicas (BLUM IR e ÖZCAN M, 2018).

Várias técnicas são disponíveis para a obtenção de elementos dentais mais simétricos e esteticamente harmônico. Quando existe o desalinhamento dos dentes, a primeira escolha são os tratamentos ortodônticos, enquanto para pacientes que buscam dentes mais claros é possível fazer o clareamento dental já que ele apresenta um processo conservador na técnica aplicada, sendo considerado por sua vez um procedimento de simples manipulação e aplicação, dos quais não acarreta modificações considerável nas estruturas próximas ao elemento periodontal nem na dentina e esmalte (CARRIJO DJ, et al., 2019).

Contudo, em vários casos a utilização de aparelhos ortodônticos e o clareamento dental não são eficazes para corresponder às expectativas e o requerimento dos pacientes. Diante disso, pode abrir mão da indispensabilidade de uma abordagem mais interceptaria como a restauração. Dessa maneira, melhorias nos aspectos tecnológicos vêm sendo feitas na área odontológica, devido a busca da estética pelos pacientes e, como resultado, os CD visam sempre utilizar materiais com aspectos ópticos parecidos aos dos dentes naturais (GREWAL N, et al., 2018).

Tais avanços conseguem ser caracterizados pela seleção dos procedimentos relacionados as técnicas diretas e indiretas na elaboração de facetas dentárias. Os procedimentos que são relacionados as técnicas diretas são aplicados através da resina composta na superfície do elemento dental, enquanto na maioria das vezes nas técnicas indiretas são confeccionadas com cerâmicas, dos quais a sua anatomia, coloração ficará relacionada à habilidade do profissional, da técnica aplicada e dos materiais que irá ser manipulado, da mesma maneira que o desempenho do técnico em prótese dentária (CHUN EP, et al., 2017). Para a confecção das restaurações dos elementos dentais anteriores, utiliza-se as resinas compostas porque possibilitam probabilidades mais esperadas do resultado final, longevidade e mais baixo custo quando se compara à cerâmica. Os compostos presentes possibilitam admirável resultado estético, pois concedem a aplicação de dessemelhantes ajustes de cores e seguimentos como opacidade e translucidez (MACHADO AC, et al., 2016).

As cerâmicas vêm se destacando por apresentarem um ótimo potencial para o restabelecimento das restaurações dentais, como serem biocompatíveis, apresentarem boa consolidação das cores e serem semelhantes aos dentes. Além do que, apresentam sua durabilidade e resistência bastante superiores quando é levado em consideração a força de tração no processo de mastigação, e expõem feição e texturas parecidos aos dentes naturais, tornando possível a efetuação dos laminados em cerâmica gradativamente bem menos encorpadas. Posto isto, há uma demanda continua por sua aplicação em restaurações cada vez mais por motivos estéticos (PACHECO AF, et al., 2014).

As restaurações feitas com cerâmicas é superior no que se refere a estética, estabilidade, duração, biocompatibilidade e grande firmeza à cor quando se compara com as resinas compostas. Ela retrata uma admirável opção para o tratamento estético, constituindo uma disposição ideal, e empregando técnicas corretas na acomodação do condicionamento ácido e nos sistemas adesivos e na hora da cimentação, porém existem um elevado problema correspondente ao grande número de trincas e fraturas (PACHECO AF, et al., 2014).

Ao serem feitas as facetas opta-se pela utilização de cerâmicas feldspática, as feldspática com leucita ou dissilicato de lítio. Especificamente, pode-se ressaltar as que são utilizadas com maior frequência, as cerâmicas feldspáticas e as que possuem reforço por dissilicato de lítio. As primeiras cerâmicas adquiridas foram as feldspáticas através de um processo de alta fusão, agregada ao metal que por sua vez integraram 
as coroas metalocerâmicas. No entanto demostrou uma menor força as flexibilidades propostas, tendo assim, sua designação limitada exclusivamente a coroas unitárias de dentes anteriores, por causa do menor estresse oclusal e consequentemente menores resultados finais indesejáveis (GOYATÁ F, et al., 2017).

As cerâmicas que são constituídas por dissilicato de lítio apresentam matriz vítrea, dos quais os cristais que estão presentes nesse composto encontram-se espalhados e trançados, tornando-se desta forma difícil o surgimento de trincas em seu interior. Além de que apresenta um ótimo padrão estético, devido a refração da luz ser correspondente com a do esmalte dental, sendo assim apto de apresentar com espontaneidade as estruturas dentárias. Além disto, consegue estabelecer firmeza mecânica ao desgaste, grande adesividade aos cimentos adesivos e tolera o emprego em próteses fixas de até três elementos dentais, coroas unitárias e facetas estéticas (GOYATÁ F, et al., 2017).

\section{Indicações e contraindicações}

Geralmente os laminados de facetas são apontadas em casos em que a estrutura ou posição de suporte do elemento dental conceda a adição de materiais restauradores para que haja o reparo de problemas sejam eles de forma, angulação, alinhamento no arco dental, a posição que se encontra, a forma simetria, além de ser levado em consideração a proporção e coloração, de maneira que evite a formação de sobre contornos. Da mesma forma são apontadas para as ocorrências de restauração em dentes que sofreram fraturas, dentes que foram traumatizados e precisa de um tratamento endodôntico além da coloração da coroa esteja escurecida, hipoplasias de esmalte, dentes que já passaram por técnicas de clareamento porém não obteve resultados satisfatórios, desgastes fisiológicos ou patológicos na dentição, lembrando que esse último a patologia deve esta tratada, para que ocorra a aplicação das facetas, como também no processo de agenesia do incisivo lateral em que se intenciona dar a aparência deste elemento dental ao dente canino, deixar de forma discreta pequenas porções de raízes que apareçam na parte cervical (MOURA AB, 2017).

Tem potencial de ser apontada também em casos de restituição das guias anteriores, visto que sua força mecânica consente, contanto que seja efetuado ajustamentos de movimentações exclusivas de forma exata, com a finalidade de que possam contribuir com a longevidade do tratamento na face incisal da faceta que foi aplicada, enfatizando e observando que no ato do processo de oclusão a mordida do paciente deve se estabelecer em esmalte ou em porcelana, se por acaso ela estiver na junção entre a porcelana com o esmalte dental ira acarretar o insucesso das intervenções feitas (GRANELL-RUÍZ M, et al., 2014).

Para que ocorra a escolha dos sistemas cerâmicos tem que ser analisada de forma bastante particularizada as áreas que irão receber o tratamento restaurador, além de que é importante observar de forma minuciosa o caso do paciente e seja feito um planejamento detalhado do tratamento proposto, dado que a prudência do profissional é obrigatório, sendo levado em deferência, visto que não pode dispensar a resistência mecânica do material tendo ele que está em compatibilidade, a forma entre a união da restauração e o elemento dental, para que seja capaz de existir maior fixação e durabilidade do tratamento feito, posto que os cuidados das estruturas constituintes dos dentes devem serem levados em consideração (CARRIJO DJ, et al, 2019).

Frequentemente não se pode aconselhar a utilização de facetas em elementos dentais que não possuam uma boa estrutura de suporte ou que apresentem esmalte não saudável, alguns hábitos na hora da anamnese devem ser levado em consideração, pois pacientes que apresentam bruxismo ou apertamento dental, pacientes com gengivite ou periodontite grave não podem utilizar essa técnica (SILVA W e CHIMELI T, 2011). Quando o paciente não dispõe de pelo menos $50 \%$ do esmalte dental não se indica esse tratamento, isso ocorre porque a dentina por si só não expõe grande adesão, tornando assim o procedimento instável, outro caso que não pode ser utilizado essa técnica são em esmaltes irregulares em toda superfície coronária, além de dentes que possuem múltiplas restaurações, oclusão, sobre mordida, em dentes tortos apinhados (MCLAREN EA e FIGUEIRA J., 2015).

\section{Custo benefício e durabilidade}

Os processos de restaurações que são executados de forma indireta, como é o caso das cerâmicas, retratam de certa forma uma taxa de sobrevivência concernente elevada chegando em média de 90 a $96 \%$, 
referindo-se a casos com 10 a 20 anos que foram acompanhados. Moura $A B$ (2017); realizou um trabalho com facetas constituídas de cerâmicas, nesse estudo ele observou e apontou uma prevalência de sobrevivência que está em torno dos 90\%, em 10 anos. Em contra partida, nesse período, quase metade dessas restaurações precisaram de manutenção e intervenções, dos quais as causas mais predominantemente das falhas foram acarretadas por fraturas, defeitos nos ângulos incisais e processos infiltrativos.

Ressalta-se ainda que os mesmos fatores encontrados em facetas cerâmicas são encontrados também nas facetas em resina composta. A grande durabilidade dos procedimentos restauradores que constituem as cerâmicas apresenta intervenções ocorridas pelo fato da efetuação de condicionantes, melhor dizendo, por alterações na concentração do tempo do ácido hidrofluorídrico que ficou exposto na hora do preparo cavitário. Se ocorrer aumento por menor que seja do tempo ou diminuição, pode ocasionar debilitação, consentindo a incidentes relacionados a microfissuras (MCLAREN EA e FIGUEIRA J., 2015).

Ao que se refere aos problemas de fraturas e fissuras em cerâmica observa-se uma taxa de 5,6 a $11 \%$ em intercorrências e os problemas nas áreas marginais representam 12 a $20 \%$, sendo esses as causas mais corriqueiras no que se refere ao fracasso. Os incidentes de fraturas e a ocorrência provocada por perda de cimento encontra-se presente também, isso se deve ao fato de que quando as facetas passaram por processo de cimentação as áreas mais externas na superfície dentaria ficaram expostas (REGINA SG, et al., 2015).

Pacientes que apresentavam bruxismo e alguns hábitos parafuncionais apresentaram fraturas, essas particularidades fazem com quer o índice de insucesso seja maior quando se compara com pacientes que não possuem essas anormalidades.

Por esse entendimento, se faz necessário disponibilizar a esses pacientes protetores oclusais, e informar a técnica de utilização. Além das fraturas descritas, a imprecisão das formas marginais são outra causa de insucesso no procedimento estabelecido, tendo sido analisado na grande maioria dos casos em facetas feitas com resinas compostas (GRANELL-RUÍZ M, et al.,2014).

A falta de uma boa elaboração do estudo do caso, os preparos sem embasamentos, a escolha não correta da cimentação, a forma de manusear e o assentamento não padronizado da aplicação de faceta no momento da etapa de cimentação, o excedente ou a supressão de cimento no decorrer da cimentação e, até mesmo, o uso de cimentos que possuem sua polimerização de forma dual são uma das causas que ocasionam grandes falhas (PERSCH DL e SOUSA NDP, 2017).

A firmeza no que se refere à fratura de um material encontra-se diretamente concernente com a eficácia de conseguir uma boa resistência as apreensões antes de verdadeiramente ocasionar uma fragmentação do material. As tentativas de diminuir e acabar com esse problema é estabelecido, nos dias de hoje, em dois princípios: Primeiro está nas modificações estruturais da cerâmica e segundo no processo de cimentações resinosas.

No que concerne a faceta indireta que são desenvolvidas com resinas compostas, os defeitos estéticos é uma das fundamentais justificativas apontadas para o seu insucesso e, deste modo, existe a relevância do processo de substituição (GREGORINI CM, 2018).

\section{Clareamento dental prévio}

O clareamento dental é uma técnica simples, contudo o CD não pode afirmar que o tratamento final será o esperado pelo paciente no resultado final. Compreender os motivos e as particularidades das modificações da tonalidade da cor é de suma relevância para que se consiga obter um resultado satisfatório (REGINA SG, et al., 2015).

Inúmeros procedimentos são feitos com o intuito de obter um clareamento mais expressivo, das técnicas vistas hoje, ressalta-se a feita de forma caseira, onde utiliza-se moldeiras individualizadas e flexíveis onde são confeccionadas de acordo dos as estruturas anatômicas dentais de cada paciente, os princípios ativos encontrados nesses agentes clareadores é peróxido de carbamida na concentração de 10 a 16\%, enquanto a feita no consultório onde utiliza-se peróxido de carbamida ou peróxido de hidrogênio nas concentração de 30 a 37\% (MCLAREN EA e FIGUEIRA J., 2015). 
Uma das causas que ocasionam as modificações das tonalidades da coloração dentaria são inúmeras e vastamente discutidas, sendo elas ocasionadas por pigmentação nicotínica, dieta do paciente, presença de biofilme, doenças provocadas por cárie, traumatismos dentoalveolar, fatores sistêmicos etc. frente a esses fundamentos e de sua eficácia confirmada, a utilização do clareamento dental antecipado a efetuação da aplicação das facetas, pode nortear a administração de métodos minimamente agressivos, visto que alcançando um potencial favorável nas estruturas dos elementos dentais o resultado será mais satisfatório tanto para o paciente quanto para o profissional (CARRIJO DJ, et al., 2019).

\section{CONSIDERAÇÕES FINAIS}

As facetas feitas com cerâmicas apresentam-se com uma superior qualidade quando é relacionada com as resinas compostas convencionais, em consequência de que às características vistas nas propriedades da porcelana são peculiares, possuindo elevada constância das cores e maior firmeza as corrosões, trincas e fraturas. Os desgastes feitos com facetas laminadas são menores quando se compara as coroas totais, desse modo a designação do clareamento dental antes da aplicação das facetas acarreta melhores resultados finais, diminuindo assim o desgaste dental. À vista disso, a aplicação das facetas indiretas demostrou-se eficaz e é na atualidade apontado como o recurso terapêutico de eleição nos casos de elementos dentais com pigmentações ou escurecidos, grandes restaurações.

\section{REFERÊNCIAS}

1. ACT A. Laminados cerâmicos na clínica integrada. Revista de Odontologia da Universidade de São Paulo, v. 30, n. 1, 2018; p. 83-94.

2. BLUM IR, ÖZCAN M. Reparative Dentistry: Possibilities and Limitations. Current Oral Health Reports, v. 5, n. 4, 2018; p. 264-269.

3. CALIXTO R, MASSING N. Longevidade das restaurações cerâmicas anteriores. Parte 1, Rev. Dental Press Estética, Araraquara, 2015; p. 18-28.

4. CARRIJO DJ, et al. Direct And Indirect Aesthetic Restorations : A Literature. Revista UNINGÁ, v. 56, n. 5, 2019 ; p. 111.

5. CHUN EP, et al. Microstructural analysis and reliability of monolithic zircônia after simulated adjustement protocols, Dent Mater. 2017.

6. GOYATÁ F, et al. Remodelação estética do sorriso com resina composta e clareamento dental em paciente jovem: relato de caso. Archives of Health Investigation, v. 6, n. 9, 2017; p. 408-413.

7. GRANELL-RUÍZ M, et al. Influence of bruxism on survival of porcelain laminate veneers. Medicina Oral, Patología Oral y Cirugía Bucal. v.19, n.5, 2014; p.426- 432.

8. GREGORINI CM. Facetas De Cerâmica Ou Resina Composta: Qual, Por Que E Como. Repositório Institucional da Universidade Federal de Santa Catarina, 2018; p. 1-85.

9. GREWAL N, et al. Surface remineralization potential of and amine fluoride containing dentifrices on primary and permanent enamel surfaces : An in vitro study. Journal of Indian Society Of Pedodontics and Preventive Dentistry, v. 14, 2018; p. 158-166.

10. JUNIOR AR. Facetas Estéticas: Cerâmica Ou Resina? Do Planejamento Ao Resultado. Trabalho de Conclusão de Curso, Repositório Institucional da Universidade Federal de Santa Catarina, 2016.

11. MACHADO AC, et al. Reabilitação estética e funcional com facetas diretas após histórico de traumatismo dentoalveolar. Revista Dentística, v. 25, n. 74, 2016; p. 154-161.

12. MCLAREN EA, FIGUEIRA J. Updating Classifications of Ceramic Dental Materials: A Guide to Material Selection, Compendium, 2015; p.400-406.

13. MOURA AB. Facetas de Resina Composta ou Cerâmicas: Qual Utilizar? Trabalho de Conclusão de Curso, Repositório Institucional da Universidade Federal de Santa Catarina, 2017.

14. OLIVEIRA CHO. Aplicação dos cimentos resinosos associados a sistemas cerâmicos condicionáveis: revisão de literatura e relato de caso. 2018.

15. PACHECO AF, et al. Técnica Indireta-direta para Resinas Compostas - Coroas Leves. International Journal of Brazilian Dentisty, v. 10, n. 1, 2014; p. 448-455.

16. PERSCH DL, et al. DE. Avaliação Das Vantagens E Desvantagens De Facetas Indiretas Em Porcelana. Trabalho de Conclusão de Curso, Repositório Institucional da Universidade Federal de Santa Catarina, 2017.

17. PERSCH DL, SOUSA NDP. Avaliação Das Vantagens E Desvantagens De Facetas Indiretas Em Porcelana. Trabalho de Conclusão de Curso, Repositório Institucional da Universidade Federal de Santa Catarina, 2017.

18. REGINA SG, et al. Tratamento Estético Com Diretas De Resina Composta - Relato De Caso Early Treatment of Class lii With Haas Associated Expander To Face Mask of Petit - Relat of Case. v. 24, n. 3, 2015; p. 27-31, 2015.

19. SCHMIDSEDER J, MARDI M. Facetas: do Planejamento a Manutenção. In:SCHMIDSEDER, J. Odontologia Estética. São Paulo: Artes médicas, 2002; 206p. Cap.5.

20. SILVA W, CHIMELI T. Transformando sorrisos com facetas diretas e indiretas. Revista Dentística On Line Brasil, v.10, n.21, 2011; p.41-43. 